\title{
Growth hormone treatment in children born small for gestational age: One center's experience
}

\author{
Sandra Stanković ${ }^{1}$, Saša Živić ${ }^{1}$, Jelena Vučić ${ }^{1}$, Vesna Cvetković ${ }^{1}$, TatjanaStanković1 ${ }^{1}$, Miodrag Stanković ${ }^{2}$
}

${ }^{1}$ Children's Hospital, Clinical Center, Niš

${ }^{2}$ Institute of Mental Health, Clinical

Center, Niš

\author{
Correspondence: \\ stankovic_sandra@yahoo.com \\ Tel.: + 38162393225 \\ Fax.: + 381184534654
}

Received: December 31, 2017

Accepted: February 9, 2018

Key words: Children SGA - Growth hormone therapy.
Objective - The aim of this paper is to present our experience in growth hormone treatment in SGA children. Patients and methods - The study enrolled 35 patients $(11.88 \pm 2.76$ years old) who were followed up during the first two years of treatment with growth hormone $(35 \mathrm{mcg} / \mathrm{kg} /$ day). Results - During the follow up period our patients showed significant growth catch up. They gained more than $1.5 \mathrm{SD}$ in height with a statistical significance of $\mathrm{P}<0.001$. Also, there was a statistically significant improvement in their body mass index (BMI) $(\mathrm{P}=0.002)$, but not BMI SD. There was a significant effect of growth hormone treatment on their insulin resistance level. HbA1c also increased significantly, but stayed within the normal range. There were no changes in LDL, HDL and total cholesterol, or triglycerides. Systolic and diastolic blood pressure did not change during the treatment period. The thyroid function test showed no significant changes. Conclusion - Although the follow up period was too short and the number of children too small to demonstrate all the short and long term consequences of growth hormone $(\mathrm{GH})$ treatment, the significant beneficial effect of GH treatment on the height of short SGA children was shown without any serious adverse effects. A significant effort should be made to improve early diagnosis of short stature in SGA children.

\section{Introduction}

Children born small for gestational age (SGA) are a very heterogeneous groups. Around ten percent of these children do not experience catch up growth, defined as a growth velocity ( $\mathrm{cm} /$ year) higher than the median for their chronological age and gender. Consequently, being born as SGA is the most significant risk factor to be short as an adult $(1,2)$. Around $20 \%$ of all adults with short stature were born as SGA. Also, being born small has been associated with an increased risk of other different disorders, such as insulin resistance, obesity, coronary heart disease, stroke, and osteoporosis, so it is important to consider these data during their health-care management $(3,4)$.

Growth hormone (GH) therapy for short-statured SGA children without evidence of catch-up growth by age 2 to 4 years has been approved by the US Food and Drug Administration since 2001 and the European Medicines Agency since 2003 (1, 2). The International Societies of Pediatric Endocrinology and the Growth Hormone Research Society consensus statement proposes that children born SGA with height below -2.5 SDs at age 2, or with height below -2 SDs 
at age 4, should be treated with growth hormone (5). It is well known that one of the major factors for a good response to growth hormone therapy is lower age, so it is suggested that all short SGA children older than four years are candidates for growth hormone therapy $(6,10)$.

The aim of this paper is to present our experience in growth hormone treatment of SGA children.

\section{Patients and methods}

\section{Patients}

The study enrolled 35 patients who were followed up during the first two years of treatment with growth hormone. The GH dose was as proposed for this diagnosis: $35 \mathrm{mcg} / \mathrm{kg} /$ day (7). The child was defined as SGA when his or her birth weight and/or birth length was below the 3rd centile of the neonatal reference chart (8). All patients were recruited during their regular visits as outpatients to a tertiary health care center (Children's Hospital, Niš, Endocrinology Department). Medical records were available for all patients for the entire follow-up period. Subjects were excluded if they had any known syndrome or chromosome anomaly. All patients were referred for growth hormone therapy. Written informed consent was obtained for all participants from their legal guardians, and the study protocol was approved by the local ethics committee $(25068 / 26)$. The mean age of the patients was $11.9 \pm 2.8$ years.

\section{Methods}

Body height and weight were measured, and body mass index (BMI) was calculated using the $\mathrm{kg} / \mathrm{m}^{2}$ formula. Blood pressure was recorded using a conventional oscillatory measurement system, positioned on the upper right arm. The size of the cuff was chosen depending on the patient's arm circumference, with the cuff bladder covering at least $40 \%$ and up to a maximum of $100 \%$ of the arm circumference. Blood samples were taken during the patients' follow up visits. Fasting HbA1c, triglycerides, total cholesterol, high density (HDL) and low density cholesterol were measured by standard laboratory methods. The basal insulin level was measured by the standard RIA method. Insulin resistance and sensitivity were calculated by the HOMA index (Homeostasis Model Assessment) and QUICKI index (Quantitative Insulin Sensitivity Check Index). The HOMA index was calculated using Matthews' formula: glucose $(\mathrm{mmol} / \mathrm{l}) \times$ insulin $(\mu \mathrm{IU} / \mathrm{ml}) / 22,5)$. QUICKI was calculated by the suggested formula $1 /$ $[\log ($ Insulin $)+\log$ (Glucose) $]$ where insulin is in $\mu \mathrm{IU} / \mathrm{ml}$ and glucose in $\mathrm{mg} / \mathrm{dl}$. Thyroid function tests TSH and FT4 were done by the chemiluminiscence method.

\section{Statistical analysis}

Statistical analyses were performed using SPSS 16.0. Values are expressed as mean SD. Comparisons between subjects were made using paired Student's t-tests or the Wilcoxon test depending on data distribution. A $P$ value of $<0.05$ was considered statistically significant.

\section{Results}

There were 22 (62.8\%) boys and 13 (37.2\%) girls. The average age was $11.88 \pm 2.76$ years. In the study group, $46 \%$ of the patients had already started puberty.

During the follow up period our patients showed significant catch up growth. They gained more than $1.5 \mathrm{SD}$ in height, with a statistical significance of $\mathrm{P}<0.001$. Also, there was a statistically significant improvement in their BMI $(\mathrm{P}=0.002)$, but not their BMI SD $(\mathrm{P}=0.311)$. Growth hormone treatment had significant effect on insulin resistance levels. 


\section{Table 1. Clinical characteristics of patients}

\begin{tabular}{|c|c|c|c|c|}
\hline \multirow{2}{*}{ Characteristics } & \multicolumn{2}{|l|}{ Treatment } & \multirow{2}{*}{$\mathrm{z} / \mathrm{t}^{*}$} & \multirow{2}{*}{$\mathrm{P}$} \\
\hline & Before & After two years & & \\
\hline Height & $130.94 \pm 14.61$ & $145.95 \pm 11.04$ & $8.239^{*}$ & $<0.001$ \\
\hline Height SD & $-1.90 \pm 0.99$ & $-0.37 \pm 1.35$ & 5.350 & $<0.001$ \\
\hline Weight (kg) & $29.00 \pm 12.92$ & $42.71 \pm 11.53$ & 5.091 & $<0.001$ \\
\hline BMI (kg/m2) & $18.40 \pm 3.79$ & $21.00 \pm 6.10$ & 3.120 & 0.002 \\
\hline BMI SD & $-0.37 \pm 1.35$ & $-0.13 \pm 1.52$ & 1.012 & 0.311 \\
\hline Glucose (mmol/l) & $4.85 \pm 0.61$ & $5.09 \pm 0.68$ & $1.676^{*}$ & 0.103 \\
\hline Basal insulin (U/I) & $20.32 \pm 7.32$ & $21.50 \pm 11.16$ & 0.022 & 0.983 \\
\hline HbA1c (\%) & $4.99 \pm 0.31$ & $5.37 \pm 0.55$ & $4.404^{*}$ & 0.006 \\
\hline HOMA & $4.39 \pm 1.66$ & $4.60 \pm 1.70$ & 2.023 & 0.043 \\
\hline QUICKI & $0.32 \pm 0.014$ & $0.32 \pm 0.014$ & 2.364 & 0.024 \\
\hline Cholesterol $(\mathrm{mmol} / \mathrm{l})$ & $4.72 \pm 0.73$ & $4.56 \pm 0.76$ & $0.867^{*}$ & 0.393 \\
\hline $\operatorname{LDL}(\mathrm{mmol} / \mathrm{l})$ & $1.57 \pm 0.56$ & $1.74 \pm 0.56$ & 1.358 & 0.183 \\
\hline $\operatorname{HDL}(\mathrm{mmol} / \mathrm{l})$ & $1.31 \pm 0.47$ & $1.46 \pm 0.50$ & 1.094 & 0.282 \\
\hline Triglycerides $(\mathrm{mmol} / \mathrm{l})$ & $0.94 \pm 0.70$ & $0.88 \pm 0.34$ & 0.494 & 0.625 \\
\hline ALT (IU/l) & $21.86 \pm 10.27$ & $20.82 \pm 12.66$ & 0.350 & 0.729 \\
\hline SBP (mmHg) & $108.79 \pm 9.92$ & $108.45 \pm 10.73$ & $0.210^{*}$ & 0.835 \\
\hline $\mathrm{DBP}(\mathrm{mmHg})$ & $68.03 \pm 9.56$ & $69.08 \pm 9.54$ & $0.823^{*}$ & 0.416 \\
\hline TSH (mU/l) & $2.49 \pm 1.76$ & $2.54 \pm 1.34$ & 0.160 & 0.874 \\
\hline fT4 (pmol /l) & $14.62 \pm 2.87$ & $14.32 \pm 1.74$ & 0.459 & 0.649 \\
\hline IGF-1 (ng/ml) & $214.08 \pm 152.59$ & $445.03 \pm 288.30$ & 2.583 & 0.010 \\
\hline
\end{tabular}

$\mathrm{Z}$ - Wilcoxon test, ${ }^{*}$ Paired t test.

The QUICKI and HOMA indexes changed significantly. HbA1c also increased significantly but stayed within the normal range. There were no changes in total, LDL and HDL cholesterol, or triglycerides. Systolic and diastolic blood pressure did not change during the treatment period. The thyroid function test showed no significant changes, but one patient developed subclinical hypothyreosis, requiring $\mathrm{L}$ thyroxin therapy. IGF-1 increased significantly but stayed below +2 SD for sex and age. Two patients had exacerbation of kyphoscoliosis, and needed further physiatrist intervention.

\section{Discussion}

Despite the fact that the growth hormone treatment is recommended for use in short
SGA children older than four years of age, there is a significant overall delay in treatment initiation. Among short SGA children in the American Norditropin Studies: WebEnabled Research (The ANSWER Program W) registry, the mean age at treatment initiation was 8.4 years (9). Among 1909 children born SGA enrolled in the Pfizer International Growth Database (KIGS; a pharmaco-epidemiological survey of children treated with $\mathrm{GH})$ the mean age at the start of GH therapy was 9.1 years (range: 3.9-13.3) (10).

Our study group was even older, with average age of 11.88 years. Knowing that older age at initiation of GH therapy is associated with significantly reduced growth response $(1,10,11)$ significant efforts should be made to improve early diagnosis of short stature in SGA children. Before treatment, 
$46 \%$ of patients had already started puberty. Peak height velocity is reached at an earlier pubertal stage and lasts for a shorter period in children born SGA. These differences lead to a shorter adult height in this group. In our study, it is not completely clear whether the increase in the average height of 1.5 SD during the follow up period is a reflection of a good response to growth hormone therapy, or the result of the pubertal growth spurt, or both. The height achieved at the end of the study period reflects a more than average pubertal growth spurt.

In our group, there were significantly more males than females. Considering the fact that parents are always more concerned about the short stature of their boys this was expected. BMI improved in the treated children, but not significantly. Insulin resistance expectedly increased (12) during the followup period but there were no adverse effects on glucose and HbA1c levels or the development of diabetes. It is well-known that growth hormone therapy has a positive metabolic and cardiovascular effect in SGA children $(1,2)$, but we did not demonstrate this during the study period. Our patients experienced the expected significant rise in IGF-1 levels, but during the follow up period they remained below 2SD for age and sex. Although the thyroid function test showed no significant changes, one patient developed subclinical hypothyreosis, requiring supplementation therapy. These results are consistent with the literature data (14).

\section{Conclusion}

Although the follow up period was too short, and the number of children was too small to demonstrate all the short and long term consequences of GH treatment, we succeeded in showing the significant beneficial effect of $\mathrm{GH}$ treatment on height and BMI in short SGA children, without any serious adverse effects. Significant efforts should be made to improve early diagnosis of short stature in SGA born children.

Authors' contributions: Conception and design: SS and SŽ; Acquisition, analysis and interpretation of data: JV, VC, and MS; Drafting the article: TS; Revising the article critically for intellectual content: SŽ and SS; Approved final version of the manuscript: SS.

Conflict of interest: The authors declare that they have no conflict of interest.

\section{References}

1. Clayton PE, Cianfarani S, Czernichow P, Johannsson G, Rapaport R, Rogol A. Management of the child born small for gestational age through to adulthood: a consensus statement of the International Societies of Pediatric Endocrinology and the Growth Hormone Research Society. J Clin Endocrinol Metab. 2007;92:804-10.

2. Saenger P, Czernichow P, Hughes I, Reiter EO. Small for gestational age: short stature and beyond. Endocr Rev. 2007;28:219-51.

3. Barker DJ. Adult consequences of fetal growth restriction. Clin Obstet Gynecol. 2006;49:270-83.

4. Barker DJ. The origins of the developmental origins theory. J Intern Med. 2007;261:412-7.

5. Lee PA, Chernausek SD, Hokken-Koelega AC, Czernichow P. International Small for Gestational Age Advisory Board consensus development conference statement: management of short children born small for gestational age, April 24-October 1, 2001. Pediatrics. 2003;111(6 Pt 1):1253-61.

6. Polak M, Blair J, Kotnik P, Pournara E, Tønnes Pedersen B, Rohrer TR. Early growth hormone treatment start in childhood growth hormone deficiency improves near adult height: analysis from NordiNet ${ }^{\oplus}$ International Outcome Study. Eur J Endocrinol. 2017;177:421-9.

7. Blankenstein O, Snajderova M, Blair J, Pournara E, Tønnes Pedersen B, Oliver Petit I. Real-life GH dosing patterns in children with GHD, TS or born SGA: a report from the NordiNet International Outcome Study. Eur J Endocrinol. 2017;177;14555.

8. Stankovic S, Zivic S, Ignjatovic A, Stojanovic M, Bogdanovic D, Novak S, et al. Comparison of weight and length at birth of non-Roma 
and Roma newborn in Serbia. Int J Pub Health. 2016;60(6):69-73.

9. Lee PA, Germak J, Gut R, Khutoryansky N, Ross J. Identification of factors associated with good response to growth hormone therapy in children with short stature: results from the ANSWER Program $^{\oplus}$. Int J Pediatr Endocrinol. 2011;2011:6.

10. Ranke MB, Lindberg A, Cowell CT, Wikland KA, Reiter EO, Wilton P, et al. Prediction of response to growth hormone treatment in short children born small for gestational age: analysis of data from KIGS (Pharmacia International Growth Database). J Clin Endocrinol Metab. 2003;88:125-31.

11. Sas TC, Gerver WJ, De Bruin R, Mulder PG, Cole TJ, De Waal W, et al. Body proportions during 6 years of GH treatment in children with short stature born small for gestational age participating in a randomised, double-blind, dose-response trial. Clin Endocrinol (Oxf). 2000;53(6):675-81.
12. Sas T, Mulder P, Aanstoot HJ, Houdijk M, Jansen $\mathrm{M}$, Reeser M, et al. Carbohydrate metabolism during long-term growth hormone treatment in children with short stature born small for gestational age. Clin Endocrinol (Oxf). 2001;54(2):243-51.

13. Sas T, Mulder P, Hokken-Koelega A. Body composition, blood pressure, and lipid metabolism before and during long-term growth hormone $(\mathrm{GH})$ treatment in children with short stature born small for gestational age either with or without $\mathrm{GH}$ deficiency. J Clin Endocrinol Metab. 2000;85:378692.

14. Allen DB, Backeljauw P, Bidlingmaier M, Biller BM, Boguszewski M, Burman P, et al. GH safety workshop position paper: a critical appraisal of recombinant human GH therapy in children and adults. Eur J Endocrinol. 2015;174:1-9. 